\title{
Comparative angiographic quantitative analysis of the immediate efficacy of coronary atherectomy with balloon angioplasty, stenting, and rotational ablation
}

\author{
V. A. W. M. Umans, B. H. Strauss, B. J. W. M. Rensing, P. de Jaegere, \\ P. J. de Feyter, and P. W. Serruys. Rotterdam, The Netherlands
}

Directional atherectomy has recently been introduced as an alternative to conventional balloon dilatation. ${ }^{1}$ It has been shown to be safe and effective when applied in human coronary arteries. ${ }^{2,3}$ It was initially hypothesized that removal of the atherosclerotic plaque would result in a better immediate result with fewer acute complications and a reduced restenosis rate compared with conventional balloon angioplasty. ${ }^{4}$ However, at the present time it is difficult to compare the respective merits of various mechanical interventions, since no randomized studies have been attempted. While awaiting these trials we used information from our quantitative angiography data base to compare patients treated with various coronary interventions. Coronary lesions from 51 patients who underwent directional atherectomy were analyzed with the computer-based coronary angiography system and matched with similar lesions treated by means of balloon angioplasty, intracoronary stenting, and rotational ablation. The immediate results from geometric assessment of the stenotic lesion by edge detection before and after atherectomy are presented and compared with the results of conventional balloon angioplasty, intracoronary stenting, and rotational ablation.

From the Catherization Laboratory, Thoraxcenter, University Hospital Dijkzigt, Erasmus University Rotterdam.

Supported in part by a grant from the Netherlands Heart Foundation (89.241) and hy research fellowship from the Heart and Stroke Foundation of Canada (Dr. Strauss).

Received for publication Jan. 14, 1991; accepted March 1, 1991.

Reprint requests: P. W. Serruys, MD, PhD, Catheterization Laboratory, Thoraxcenter, Erasmus University Rotterdam, PO Box 1738, 3000 DR Rotterdam, The Netherlands.

4/1/30486

\section{METHODOLOGY}

Patient group. From September 1989 through September 1990, a total of 51 patients (43 men and 8 women) underwent an atherectomy procedure for symptomatic coronary artery disease. Three patients underwent two procedures and one patient had three procedures. The atherectomy procedure was successful in 54 of the 56 procedures (postprocedural diameter of stenosis $<50 \%)$. The mean age $( \pm S D)$ was $58.2( \pm 10.1)$ years. At the time of atherectomy 21 patients were in New York Heart Association functional class IV, 11 were in class III and 19 were in class II. Coronary angiography showed one-vessel disease in 39 patients, two-vessel disease in eight, and threevessel disease in four. The site of obstruction was located in the left anterior descending coronary artery in 31 patients, in the right coronary artery in 13 , in the circumflex artery in nine, and in the venous bypass graft in three.

Atherectomy procedure. After administration of local anesthesia, an $11 \mathrm{~F}$ sheath was inserted into the femoral artery. All patients received $250 \mathrm{mg}$ acetylsalicylic acid and 10,000 $\mathrm{U}$ heparin intravenously. Intracoronary injection of isosorbide dinitrate was given to minimize any possible spasm. After initial angiograms in multiple views were obtained, a special $11 \mathrm{~F}$ guiding catheter was placed into the ostium of the coronary artery. Under fluoroscopy the guide wire was advanced into the distal part of the artery. Then the atherectomy device was directed over the guide wire and positioned across the stenosis. The support balloon was then inflated up to $0.5 \mathrm{~atm}$, the cutter was retracted, and the balloon inflation pressure was increased to 2 to $3 \mathrm{~atm}$. The driving motor was activated, and the rotating cutter was slowly advanced to cut and collect the protruding atheroscle- 
rotic lesion in the collecting chamber located at the tip of the catheter. After every pass the balloon was deflated and either removed or repositioned. On average $6.1 \pm 2.9$ passes in multiple directions were performed across a stenosis. Atherectomy was considered successful when the residual stenosis was less than $50 \%$ after tissue retrieval. After atherectomy the arterial and venous sheaths were usually left in place for 6 hours. Patients were monitored for 24 hours, and ECGs and cardiac enzyme levels were obtained twice a day. Nifedipine was given every 2 hours after the procedure, and patients continued to receive aspirin medication for 1 year.

Quantitative coronary anglography. Quantitative analysis of the coronary segments was performed with the computer-based Coronary Angiography Analysis System, which was previously described in detail. ${ }^{5,6}$ In essence boundaries of a selected coronary artery segment (Fig. 1) are detected automatically from optically magnified and video-digitized regions of interest ( $512 \times 512$ pixels) of a cineframe. The absolute diameter of the stenosis (in millimeters) is determined with the use of the guiding catheter as a scaling device. Calibration of the catheter in absolute values (in millimeters) is achieved by comparing the mean diameter of the guiding catheter in pixels with the measured size in millimeters. Each individual catheter is measured by a micrometer. To correct the detected contour of the arterial and catheter segments for pincushion distortion, a correction vector is computed for each pixel based on a computer-processed cineframe with a centimeter grid placed against the input screen of the image intensifier. Because the functional significance of a stenosis is related to the expected normal cross-sectional area of a vessel at the point of obstruction, we use a computer estimation of the original dimension of the artery at the site of the obstruction to define the interpolated reference area. The percentage diameter and area stenosis, as well as the cross-sectional area (in millimeters squared), are then calculated. The length of the lesion (in millimeters) is determined from the diameter function on the basis of a curvature analysis. By use of the reconstructed borders of the vessel, the computer calculates the symmetry coefficient for the stenosis. The symmetry index ranges from zero (totally eccentric stenosis) to one (symmetric). The degree of coronary bend is assessed by the curvature value at the site of the obstruction. This parameter is computed as the average value of all the individual curvature values along the center line of the coronary segment, with the curvature defined as the first derivative of the tangent as it moves along the center line, which for a circle is equal to the reciprocal of the radius.

Hemodynamic assessment. The hemodynamic results were determined as described earlier. ${ }^{7-10}$ Briefly the theoretical pressure decrease was calculated by means of the arteriogram and digital computation according to the formula: Pgrad $=Q$. $(R p+Q$. Rt), where Pgrad is the theoretical transstenotic pressure decrease $(\mathrm{mm} \mathrm{Hg})$ over the stenosis, $Q$ is the mean coronary flow $(\mathrm{ml} / \mathrm{sec}), \mathrm{Rp}$ is the Poiseuille resistance, and Rt is the turbulence resistance. The theoretical transstenotic pressure decrease was calculated for a theoretical blood flow of 1,2 and $3 \mathrm{ml} / \mathrm{sec}$. The Poiseuille and turbulence contributions to flow resistance were determined from stenosis geometry assessed by quantitative coronary angiography.

Matching process. To avoid patient selection bias we selected populations with comparable baseline stenosis characteristics. The coronary artery tree was subdivided into 15 segments according to the American Heart Association guidelines. The lesions were individually matched according to the location of the stenosis and the reference diameter. Matching was considered adequate if the mean difference of the reference diameter between the groups was identical. Three patients who were treated for bypass graft stenosis and two patients with an unsuccessful procedure were excluded from the matching process. Thus 51 lesions treated with intracoronary atherectomy were individually matched with "twin" lesions treated with balloon angioplasty or self-expandable stent. The group treated with the Rotablator (Heart Technology Inc., Bellevue, Wash.) was not individually matched, since only seven patients were included. Their results are represented as a group. Currently the Thoraxcenter angiographic registry contains quantitatively assessed stenosis data for 2300 patients treated either by angioplasty $(n=1847)$, intracoronary stenting $(n=406)$, directional atherectomy $(n=56)$, or rotational ablation $(n=7)$.

\section{Device profiles}

Atherectomy devices. In 50 of 51 patients undergoing atherectomy a $6 \mathrm{~F}$ catheter was used, whereas in one patient a $7 \mathrm{~F}$ atherectomy device was employed. The mean diameter of the atherectomy device was 2.1 $\mathrm{mm}$ by quantitative angiographic assessment.

Balloon angioplasty. The transverse diameter of the deflated balloon is an important determinant as to whether a stenosis can be crossed. Currently used balloons have favorable profile characteristics as expressed by their small diameter $(1.0 \mathrm{~mm}$ : ranging from 0.8 to $1.1 \mathrm{~mm}$ ). The balloon sizes were matched to the reference diameter with the goal of achieving 

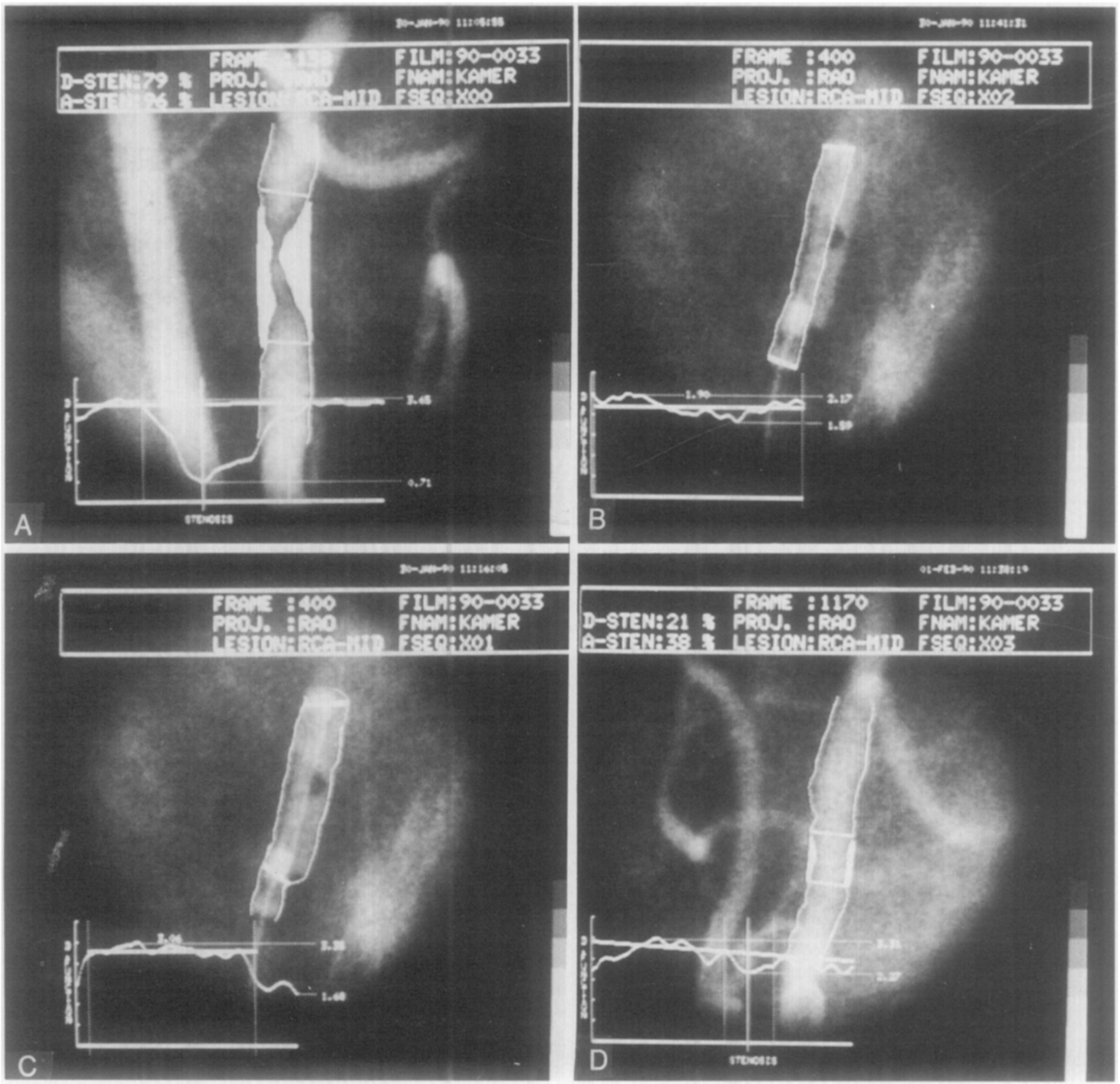

Fig. 1. A, Detected contours superimposed on original video image for a representative right coronary artery stenosis filmed in right anterior oblique projection before directional atherectomy. Diameter function is shown at bottom. White area is measure for "atherosclerotic plaque." Minimum luminal diameter (verticle line) is $0.71 \mathrm{~mm}$, corresponding to diameter stenosis of $79 \%$ and area stenosis of $96 \%$. B, Contour analysis of intracoronary atherectomy device without inflated support balloon. This represents first or "prefunctional" stage of intracoronary intervention characterized by intrinsic diameter of device. C, Contour analysis of intracoronary filmed atherectomy device with inflated support balloon. Beneath this is shown diameter function. Mean diameter is $3.06 \mathrm{~mm}$. This analysis represents second or "operational" stage in which atherectomy device exhibits its mode of action. D, Single-frame angiogram of right coronary artery filmed in right anterior oblique projection after directional atherectomy. Minimum luminal diameter increased to $2.27 \mathrm{~mm}$, corresponding to diameter stenosis of $21 \%$ and area stenosis of $38 \%$,

a ratio of 1:1 (inflated balloon diameter:artery diameter). The following balloon diameters were used in this study population: $2.0 \mathrm{~mm}(\mathrm{n}=1), 2.5 \mathrm{~mm}$ $(\mathrm{n}=12), 3.0 \mathrm{~mm}(\mathrm{n}=27), 3.4 \mathrm{~mm}(\mathrm{n}=1), 3.5(\mathrm{n}=9)$, and $4.0 \mathrm{~mm}(\mathrm{n}=1)$.
Stenting. The self-expanding stent is constrained on a small-diameter delivery catheter but assumes its unconstrained larger diameter up to $6 \mathrm{~mm}$ when the constraining membrane is removed. The stent catheter profile mounted on its delivery device is 1.57 


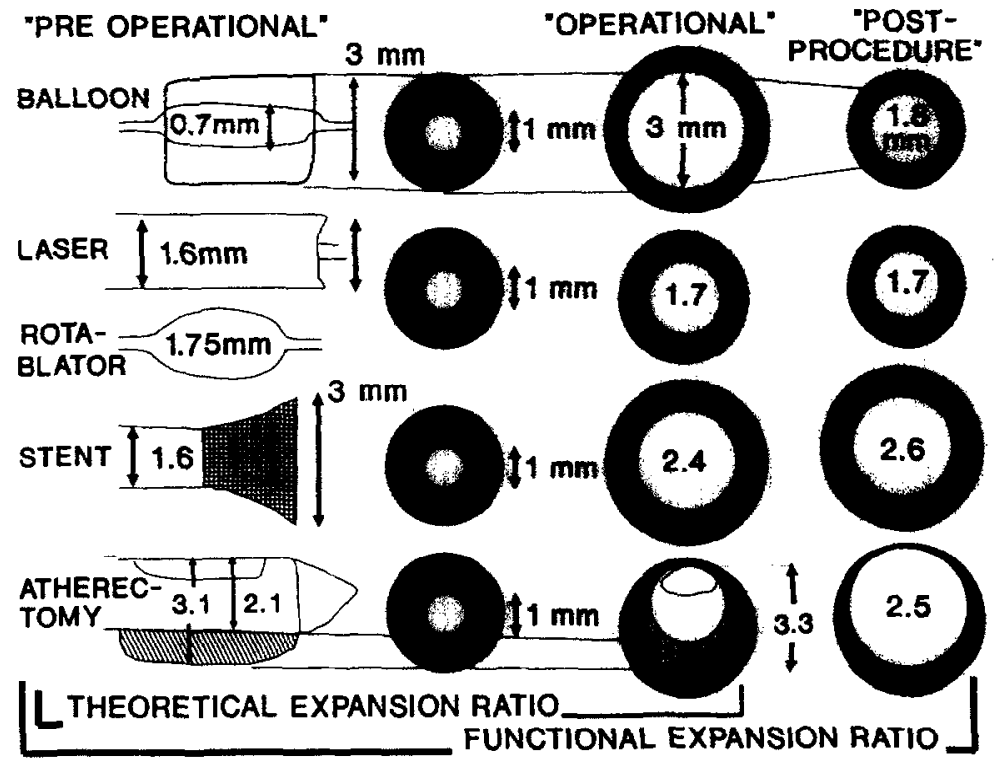

Fig. 2. Schematic representation of concept of functional and theoretical expansion ratio of various intracoronary intervention techniques. First or "prefunctional" stage is characterized by introduction of device. In becoming operational some devices get expanded (atherectomy, balloon, stent), whereas others maintain their original dimensions (laser, Rotablator). End result is determined by recoil phenomenon and vascular reactivity. After device is removed maximum acute effect may be partially lost because of elastic recoil vessel. Expansion ratio is subdivided into theoretical expansion ratio, which is determined by operational device, and functional expansion ratio, which takes into account elastic recoil phenomenon and describes net result.

mm. ${ }^{11}$ In the 51 study patients the unconstrained diameters were $3.0 \mathrm{~mm}(\mathrm{n}=5), 3.5 \mathrm{~mm}(\mathrm{n}=29), 4.0$ $\mathrm{mm}(\mathrm{n}=9), 4.5 \mathrm{~mm}(\mathrm{n}=1)$, and $5.0 \mathrm{~mm}(\mathrm{n}=3)$; the diameter was unknown in four. The stent sizes were selected on the basis of the size of the arterial segment, taking into account that the stent in its unconstrained form must have a diameter $0.5 \mathrm{~mm}$ larger than the reference diameter of the stented vessel. ${ }^{11}$

Rotational ablation. With rotational ablation the device consists of a rotating abrasive burr of variable profile characteristics (from 1.5 to $3.5 \mathrm{~mm}$ ). In this series the largest burr size used was $2.25 \mathrm{~mm}$. Choice of burr size was selected according to the reference diameter.

Quantitative ascesement of the expansion ratio of the various devices. Recently the concept of the expansion ratio has been addressed. ${ }^{12}$ Briefly the mechanism of all intracoronary interventions may be divided into three stages. The first or "prefunctional" stage is characterized by the introduction of the device. The device is not yet operational, and its intrinsic dimensions determine to what extent the device may be introduced into the coronary tree. During the introduction of a bulky device across a stenotic lesion, some degree of dilatation occurs as a direct result of a Dotter effect. The second or "operational" stage starts when the device becomes operational and exhibits its specific mode of action (dilatation, cutting, ablation, vaporization). In becoming operational the diameter of the device may expand (atherectomy, balloon, stent) or maintain its original dimensions (laser, rotational ablation). During this stage the maximum effect of the device is achieved. The final result after removal of the device is then determined by the recoil phenomenon and vascular reactivity. Consequently the net luminal gain will be less than the initial gain when the device is operational (Fig. 2).

To distinguish the acute effect of the various devices from the vascular reactivity and recoil phenomenon, we subdivided the expansion ratio into the theoretical expansion ratio, which occurs during the "operational" stage, and the functional expansion ratio, which takes into account the elastic recoil phenomenon and describes the net result. ${ }^{13}$ Both the theoretical and functional ratios were assessed for all interventional devices used in our study. The maximum achievable diameter of the vessel is calculated according to the diameter of the operational device while it is active. In the case of balloon angioplasty and self-expandable stent, this corresponds to the diameter of the inflated balloon and to the unconstrained diameter of the self-expandable stent. For atherectomy this was assessed by intracoronary quan- 
Table I. Effect of directional coronary atherectomy on 55 obstructive lesions

\begin{tabular}{lccccccc}
\hline & $\begin{array}{c}\text { Extent } \\
(\mathrm{mm})\end{array}$ & $\begin{array}{c}M L D \\
(\mathrm{~mm})\end{array}$ & $\begin{array}{c}\text { Reference } \\
(\mathrm{mm})\end{array}$ & $\begin{array}{c}D S \\
(\%)\end{array}$ & $\begin{array}{c}\text { MLCA } \\
\left(\mathrm{mm}^{2}\right)\end{array}$ & $\begin{array}{c}\text { Plaque area } \\
\left(\mathrm{mm}^{2}\right)\end{array}$ & $\begin{array}{l}\text { Symmetry index } \\
\text { Sm }\end{array}$ \\
\hline Mean \pm SD & & & & & & & \\
Before atherectomy & $6.4 \pm 2.5$ & $1.1 \pm 0.4$ & $3.0 \pm 0.6$ & $63 \pm 11$ & $1.1 \pm 0.8$ & $8.8 \pm 5.6$ & $0.6 \pm 0.3$ \\
After atherectomy & $4.7 \pm 2.1$ & $2.5 \pm 0.5$ & $3.2 \pm 0.4$ & $22 \pm 15$ & $5.2 \pm 1.8$ & $2.6 \pm 2.1$ & $0.7 \pm 0.2$ \\
$p$ Value & $<0.00001$ & $<0.00001$ & 0.03 & $<0.00001$ & $<0.00001$ & $<0.00001$ & NS \\
\hline
\end{tabular}

MLD, Minimal luminal diameter; DS, diameter stenosis; MLCA, minimal cross-sectional area; SD, standard deviation; NS, not significant.

Table II. Hemodynamic results immediately after directional coronary atherectomy

\begin{tabular}{lccccc}
\hline & & & \multicolumn{2}{c}{ Pressure gradient (mm Hg) } \\
\cline { 5 - 6 } & $\begin{array}{c}\text { Poiseuille resistance } \\
\left(\text { dynes } / \mathrm{sec} / \mathrm{cm}^{-5}\right)\end{array}$ & $\begin{array}{c}\text { Turbulent resistance } \\
\left(\text { dynes } / \mathrm{sec} / \mathrm{cm}^{-5}\right)\end{array}$ & $\begin{array}{c}\text { Flow } \\
(1 \mathrm{ml} / \mathrm{sec})\end{array}$ & $\begin{array}{c}\text { Flow } \\
(2 \mathrm{ml} / \mathrm{sec})\end{array}$ & $\begin{array}{c}\text { Flow } \\
(3 \mathrm{ml} / \mathrm{sec})\end{array}$ \\
\hline Mean \pm SD & & & & & \\
Before atherectomy & $39.2 \pm 124.8$ & $20.6 \pm 59.7$ & $48.0 \pm 154.5$ & $105.5 \pm 380.9$ & $197.5 \pm 697.0$ \\
After atherectomy & $0.3 \pm 0.4$ & $0.05 \pm 0.17$ & $0.4 \pm 0.1$ & $0.6 \pm 1.0$ & $1.0 \pm 1.6$ \\
$p$ Value & 0.025 & 0.013 & 0.026 & $<0.01$ & 0.042 \\
\hline SD, Standard deviation. & & & &
\end{tabular}

titative analysis during inflation of the support balloon. The Rotablator does not alter its diameter while operational. The postprocedure diameter has been measured immediately after withdrawal of the device. For example, when the diameter of an intracoronary atherectomy device increases from $2.1 \mathrm{~mm}$ to $3.5 \mathrm{~mm}$ on inflation of the balloon, the maximum achievable vessel diameter becomes $3.5 \mathrm{~mm}$. However, the final luminal diameter at the end of the procedure measures $2.6 \mathrm{~mm}$. Thus the theoretical and functional expansion ratios are $1.7(3.5 / 2.1)$ and $1.2(2.6 / 2.1)$, respectively.

Statistical analysis. All values are expressed as mean values \pm 1 standard deviation. Morphologic and hemodynamic variables before and after atherectomy were compared by the paired Student's $t$ test. Comparisons of the severity of minimum luminal diameter, area of plaque, and diameter of stenosis among the groups were performed by means of analysis of variance. If significant differences were found, the unpaired Student's $t$ test was applied. Differences were considered statistically significant at $p<0.05$.

\section{OBSERVATIONS}

Directional atherectomy. Fifty-six lesions in 51 patients were studied, and a mean of 1.4 angiographic projections per lesion were analyzed. The morphologic and hemodynamic data are presented in Tables I and II, respectively. The mean values for the minimum luminal diameter before and after atherectomy were $1.1 \pm 0.4 \mathrm{~mm}$ and $2.5 \pm 0.4 \mathrm{~mm}$, respectively.
This morphologic improvement was associated with a significant decrease in the calculated Poiseuille and turbulent resistance, as well as a theoretical transstenotic gradient decrease for a theoretical flow of 1 $\mathrm{ml} / \mathrm{sec}$.

Atherectomy versus angioplasty and stenting. Matching according to lesion distribution and reference diameter was considered adequate since the reference diameter was equal in all groups (3.0 \pm 0.6 $\mathrm{mm}$ ), whereas the mean difference for this parameter between the groups was $0.0 \pm 0.1 \mathrm{~mm}$. No preprocedural differences were found among patients undergoing atherectomy, balloon angioplasty, and stenting with regard to minimum luminal diameter $(1.2 \pm 0.4$ $\mathrm{mm}$ vs $1.2 \pm 0.3 \mathrm{~mm}$ vs $1.2 \pm 0.5 \mathrm{~mm}$ ), diameter stenosis ( $63 \pm 10 \%$ vs $62 \pm 10 \%$ vs $60 \pm 12 \%$ ), area plaque $\left(8.8 \pm 5.8 \mathrm{~mm}^{2}\right.$ vs $8.2 \pm 4.5 \mathrm{~mm}^{2}$ vs $8.4 \pm 4.5$ $\left.\mathrm{mm}^{2}\right)$, and symmetry value $(0.5 \pm 0.3$ vs $0.6 \pm 0.3 \mathrm{vs}$ $0.5 \pm 0.2$ ). Curvature value was less in the atherectomy group compared with the angioplasty group $(15.9 \pm 7.0$ vs $22.2 \pm 13.1)$. Table III represents the changes in minimum luminal diameter, diameter of stenosis, and area plaque induced by presently available intracoronary interventional devices as assessed by quantitative angiography in our institution. A significantly larger gain in lumen diameter was achieved by directional atherectomy and stenting compared with balloon angioplasty $(1.4 \mathrm{~mm}$ and 1.3 $\mathrm{mm}$ vs $0.7 \mathrm{~mm} ; p<0.00001$ ). Rotational ablation resulted in the smallest luminal increment (1.2 \pm 0.4 $\mathrm{mm}$ to $1.6 \pm 0.1 \mathrm{~mm}$ ). 
Table 1II. Comparative quantitative analysis of the immediate results of atherectomy, angioplasty, and stenting

\begin{tabular}{|c|c|c|c|c|c|c|}
\hline & \multicolumn{2}{|c|}{ Atherectomy } & \multicolumn{2}{|c|}{$P T C A$} & \multicolumn{2}{|c|}{ Stenting } \\
\hline & Before & After & Before & After & Before & After \\
\hline $\mathrm{MLD}(\mathrm{mm})$ & $1.2 \pm 0.4$ & $2.6 \pm 0.4$ & $1.2 \pm 0.3$ & $1.9 \pm 0.4^{*}$ & $1.2 \pm 0.5$ & $2.5 \pm 0.4 \dagger$ \\
\hline $\operatorname{AP}\left(\mathrm{mm}^{2}\right)$ & $8.8 \pm 5.8$ & $2.6 \pm 2.1$ & $8.2 \pm 4.5$ & $5.3 \pm 4.0^{*}$ & $8.4 \pm 4.5$ & $3.5 \pm 2.4 \dagger$ \\
\hline $\operatorname{DS}(\%)$ & $63 \pm 10$ & $20 \pm 11$ & $62 \pm 10$ & $36 \pm 11^{*}$ & $60 \pm 12$ & $20 \pm 9+$ \\
\hline
\end{tabular}

PTCA, Percutaneous transluminal coronary angioplasty; MLD, minimal luminal diameter; AP, area plaque; DS, diameter stenosis. $* p<0.00001$ atherectomy versus PTCA and stenting versus PTCA.

to Value not significant for atherectomy versus stenting.

Table IV. Quantitative assessment of the theoretical and functional expansion ratio of intracoronary devices

\begin{tabular}{llcccc}
\hline \multicolumn{1}{c}{ Intervention } & $\begin{array}{c}\text { Device } \\
\text { profle }(\mathrm{mm})\end{array}$ & $\begin{array}{c}\text { Maximum diameter } \\
\text { achieved }(\mathrm{mm})^{*}\end{array}$ & $\begin{array}{c}\text { Postinterventional } \\
\text { diameter }(\mathrm{mm})^{*}\end{array}$ & $\begin{array}{c}\text { Expansion ratio } \\
\text { Theoretical }\end{array}$ \\
\hline Balloon angioplasty & $1.0(0.8-1.1)$ & $2.8 \pm 0.5$ & $1.9 \pm 0.4$ & 2.9 & 1.9 \\
Self-expandable stents & 1.6 & $3.3 \pm 0.3 \dagger$ & $2.5 \pm 0.4$ & 2.5 & 1.6 \\
Directional atherectomy & $2.1(2.0-2.4)$ & $3.3 \pm 0.5$ & $2.6 \pm 0.4$ & 1.6 \\
Rotational ablation & $2.0(1.5-2.3)$ & $1.9 \pm 0.4$ & $1.6 \pm 0.2$ & 1.0 & 0.8 \\
\hline
\end{tabular}

*Assessed by quantitative coronary analysis.

+Unconstrained stent diameter.

Quantitative enalyeis of the theoretical and functional expansion ratio. Quantitative analysis of the intracoronary atherectomy device shows a mean diameter of $2.1 \mathrm{~mm}$, which increases to $3.3 \mathrm{~mm}$ after inflation of the support balloon. Compared with the other devices atherectomy has a larger catheter delivery system, which limits the theoretical and effective expansion ratio (1.6 and 1.2, respectively). Balloon angioplasty and stenting give superior expansion ratios, since they are introduced on smaller delivery syatems. Rotational ablation had the lowest expansion ratio, since the Rotablator does not change in size while in operation (Table IV).

\section{COMMENTS}

Over the past 5 years there has been a rapid increase in the development of new interventional devices aimed at supplementing conventional balloon dilatation. This progress in technology has resulted in the introduction of directional coronary atherectomy, intracoronary stenting, rotational coronary ablation, and laser-assisted angioplasty. Clinical studies have demonstrated the feagibility and safety of these interventions; however, the relative efficacy of each technique remains to be assessed.

Edge detection versus videodensitometry. The immediate efficacy of the various coronary interventions should be assessed by reproducible quantitative angiographic measurements. ${ }^{14}$ Visual estimation of the severity of stenosis alone results in unacceptable variation in the assessment of changes in coronary artery lesions. To obtain values that are objective and reproducible, a computer-assisted technique that uses automated edge detection or videodenaitometry should be applied. ${ }^{15}$ Whether edge-detection techniques are inferior to videodensitometry remains an unresolved issue. Results of a previous study ${ }^{5}$ demonstrated that the edge-detection method correlates well with densitometric analysis of the severity of stenosis before angioplasty. However, after angioplasty discrepancies between these types of measurements may be observed when a single-plane view is used. ${ }^{16}$ Recently we have shown that a linear relationship exists between edge detection and videodensitometry both before and after atherectomy, although the strength of this relationship deteriorates slightly after atherectomy. ${ }^{17}$ Therefore we felt justified in assessing the immediate efficacy of coronary atherectomy by edge-detection analysis.

Atherectomy versus angloplasty and stenting. With the increasing number of interventional modalities, current indications and patient selection become difficult. This study demonstrates the important finding that atherectomy and stenting result in a larger increase in minimum luminal diameter when compared with results of balloon angioplasty (1.4 and $1.3 \mathrm{~mm}$ vs $0.7 \mathrm{~mm}, p<0.00001$ ). In addition, no differences in the postinterventional angiographic results were observed between groups undergoing atherectomy and stenting. Results of this study con- 
firm the findings of Muller et al. ${ }^{18}$; however, with our more refined matching technique individual atherectomy lesions were directly compared with angiographically similar lesions treated by angioplasty or stenting. Although a randomized trial is the optimum method for comparing the short- and long-term results of new interventional techniques, matching based on quantitative analysis might become an acceptable alternative while patients are awaiting these trials. With the use of this matching program we selected populations with comparable baseline stenosis parameters. The lesions were adequately matched, since no differences were found in reference diameter, minimal luminal diameter, area plaque, and symmetry index among the three groups. Whether the superior immediate results after atherectomy and stenting will be associated with a reduction in restenosis remains to be assessed in random trials.

Intracoronary devices. The expansion ratio is an important concept that relates the final effect of the intracoronary device on the arterial diameter to the size of the catheter required to deliver this effect. ${ }^{12}$ The maximum effect of the device may be partially lost because of the elastic recoil of the vessel. The expansion ratio has been subdivided into two components, theoretical and functional, to separate these influences. ${ }^{13}$ Balloon angioplasty and stenting give extremely favorable theoretical and functional expansion ratios (2.9 and 1.9 vs 2.5 and 1.6, respectively), since they may be delivered on low-profile catheters. The directional atherectomy device is more limited by the size of the housing and collecting chamber. The dimensions of the rotational atherectomy device do not change during the operation and therefore this procedure exhibits the lowest theoretical expansion ratio.

Although balloon angioplasty has the most favorable expansion ratio, the final result is profoundly influenced by the elastic recoil of the vessel. ${ }^{19,20}$ Stenting and atherectomy appear to be more effective in resisting elastic recoil, although the mechanisms are likely different. Stenting effectively prevents this recoil phenomenon presumably because of its scaffolding function and its intrinsic dilating effect. ${ }^{10,13}$ By physically removing tissue atherectomy appears to diminish the potential elastic recoil effect. However, the actual diameter of the atherectomy device limits its suitability in smaller coronary arteries.

Limitations. There are several limitations of this study. First, it is an uncontrolled retrospective observational study limited to a subset of patients who underwent successful coronary intervention. Although matching for angiographic variables is a promising technique to assess the efficacy of intracoronary interventions, patient- and procedurerelated variables should also be included in the analysis. Second, this study is based on early experiences with atherectomy and stenting. Future design changes and improved operator experience may further improve the immediate and long-term results. Finally, the efficacy of all intracoronary interventions will be limited by the problem of restenosis, which necessitates careful and complete angiographic follow-up. Thus controlled clinical trials are imperative in the future to determine the immediate angiographic results and the long-term efficacy of these interventions and whether any benefit can be shown in particular patient subgroups.

Conclusions. Quantitative angiographic assessment of the immediate results after directional atherectomy shows significant improvement in the geometry and hemodynamics of stenosis. While patients are awaiting randomized trials, matching on the basis of quantitative analysis might become an acceptable alternative for objective and comparative assessment of various interventional techniques. In matched populations directional atherectomy and stenting appear to be more effective intracoronary interventional devices than balloon angioplasty based on the immediate result; however, atherectomy is limited in smaller coronary vessels by its larger size. Theoretically stenting has the most favorable characteristics as a dilating device, although its clinical use is limited by its more complicated patient management.

\section{SUMMARY}

Interventional cardiology has branched in two directions: devices that primarily dilate coronary stenoses and those that debulk coronary tissue. Presently the optimum coronary intervention has not been found. While patients are awaiting randomized trials, a comparison based on matched quantitative coronary analysis may be useful to evaluate results of new interventional techniques. Therefore we compared 51 patients undergoing atherectomy with individually matched patients who were undergoing balloon angioplasty and stenting. The lesions were matched according to location of stenosis and reference diameter. Atherectomy and stenting resulted in larger gains in minimal luminal diameter compared with conventional balloon angioplasty. The minimal luminal diameter was increased from $1.2 \pm 0.4 \mathrm{~mm}$ to $2.6 \pm 0.4 \mathrm{~mm}$ in the atherectomy group and from $1.2 \pm 0.3 \mathrm{~mm}$ to $1.9 \pm 0.4 \mathrm{~mm}$ in the angioplasty group $(p<0.00001)$. Atherectomy and stenting resulted in similar gains in minimum luminal diameter (1.4 $\mathrm{mm}$ vs $1.3 \mathrm{~mm}, p=\mathrm{NS}$ ). In addition, atherec- 
tomy and stenting appear to be more effective in resisting elastic recoil because of tissue removal and an intrinsic dilating effect, respectively. In matched populations directional atherectomy and stenting appear to be more effective intracoronary interventional devices than balloon angioplasty based on the immediate results. However, atherectomy is limited in smaller coronary vessels because of its larger size.

We thank Eline Montauban van Swijndregt, Marie Angele Morel, and the Cardialysis Core Laboratory for the quantitative angiographic analysis and Marjolein Wapenaar for her secretarial assistance.

\section{REFERENCES}

1. Simpson JB, Johnson DE, Thapliyal HV, Marks Ds, Braden LJ. Transluminal atherectomy: a new approach to the treatment of atherosclerotic vascular disease [Abstract]. Circulation 1985;72(suppl III):III-146.

2. Vlietstra RE, Abbotsmith CW, Douglas JC, Hollman JL, Muller D, Safian R, Selmon MR. Complications with directional coronary atherectomy: experience at eight centers [Abstract]. Circulation 1989;80(suppl II):II-582.

3. Safian RD, Gelbfish JS, Erny RE, Schnitt SJ, Schmidt D, Baim DS. Coronary atherectomy: clinical, angiographic and histologic findings and observations regarding potential mechanisms. Circulation 1990;82:69-79.

4. Robertson GC, Hinohara T, Selmon MR, Johnson DE, Simpson JB. Directional coronary atherectomy. In: Topol EJ, ed. Textbook of interventional cardiology. Philadelphia: WB Saunders Company, 1990:563-79.

5. Serruys PW, Reiber JHC, Wijns W, van den Brand $M$, Kooijman CJ, ten Kate HJ, Hugenholtz PG. Assessment of percutaneous transluminal coronary angioplasty by quantitative coronary angiography: diameter versus densitometric area measurements. Am J Cardiol 1984;54:482-8.

6. Reiber JHC, Serruys PW, Kooyman CH, Wijns W, Slager CJ, Gerbrands JJ, Schuurbiers JCH, den Boer A, Hugenholtz PG. Assessment of short-, medium- and long-term variations in arterial dimensions from computer-assisted quantitation of coronary cineangiograms. Circulation 1985;71:280-8.

7. Zijlstra F, Reiber JHC, Serruys PW. Does intracoronary papaverine dilate epicardial coronary arteries? Implications for the assessment of coronary flow reserve. Cathet Cardiovasc Diagn 1988;14:1-12.
8. Serruys PW, Wijns W, Reiber JHC, de Feyter P, van den Brand $M$, Piscioni F, Hugenholtz $P G$. Values and limitations of trans-stenotic pressure gredients measured during percutaneous coronary angioplasty. Herz 1985;10:337-42

9. Wijns W, Serruys PW, Reiber JHC, van den Brand M, Simoons M, Kooijman CJ, Balakumaran K, Hugenholtz PG. Quantitative angiography of the left descending coronary artery: correlations with pressure gradient and results of exercise thallium scintigraphy. Circulation 1985;71:273-9.

10. Serruys PW, Juilliere Y, Bertrand ME, Puel J, Rickards A, Sigwart U. Additional improvement of stenosis geometry in human coronary arteries by stenting after balloon dilatation. Am J Cardiol 1988;61:71G-6G.

11. Serruys PW, Strauss BH, Beatt KJ, Bertrand ME, Puel J, Rickards AF, Meier B, Goy JJ, Vogt P, Kappenberger L, Sigward U. Angiographic follow-up after placement of a self-expanding coronary artery stent. $N$ Engl $J$ Med 1991;1:28-34.

12. Schatz RA. A view of vascular stent. Circulation 1989;79:44557.

13. Serruys PW, Strauss BH, van Beusekom HM, van der Giessen. Stenting of coronary arteries: has a modern Pandora's box been opened? J Am Coll Cardiol 1991;17:143B-54B.

14. Beatt KJ, Serruys PW, Hugenholtz PG. Restenosis after cor onary angioplasty: new standards for clinical studies. J Am Coll Cardiol 1990;15:491-8.

15. Smalling RW. Can the immediate efficacy of coronary angioplasty be adequately assessed? J Am Coll Cardiol 1987;10: 261-3.

16. Strauss BH, Juilliere Y, Rensing B, Reiber JHC, Serruys PW. Assessment of coronary stenting by quantitative coronary angiography: edge detection versus densitometry. Reevaluation of an old controversy. Am J Cardiol 1991;67:484-90.

17. Umans VAWM, Strauss BH, de Feyter PJ, Serruys PW. Assessment of directional coronary atherectomy by quantitative coronary angiography: edge detection versus videodensitometry. Am J Cardiol 1991 (in press)

18. Muller DWM, Ellis SG, Debowey DL, Topol EJ. Quantitative angiographic comparison of the immediate success of coronary angioplasty, coronary atherectomy and endoluminal stenting. Am J Cardiol 1990;66:938-42.

19. Rensing BJ, Serruys PW, Beatt KJ, Suryapranata H, Laarman GJ, de Feyter PJ. Densitometrically observed differences in elastic recoil of the three main coronary arteries after percutaneous transluminal coronary angioplasty. [Abstract]. J Am Coll Cardiol 1990;15(suppl A):43A.

20. Rensing BJ, Hermans WRM, Beatt KJ, Laarman GJ, Suryapranata $H$, van den Brand M, de Feyter PJ, Serruys PW. Quantitative angiographic assessment of elastic recoil after PTCA. Am J Cardiol 1990;66:1039-45. 